\title{
Regulation of apoptosis by long non-coding RNA GAS5 in breast cancer cells:
}

\section{implications for chemotherapy}

Mark R. Pickard* \& Gwyn T. Williams*

Apoptosis Research Group, Institute of Science and Technology in Medicine, Huxley

Building, School of Life Sciences, Keele University, Keele ST5 5BG, United Kingdom.

*Corresponding authors:

M.R.Pickard: E-mail: m.r.pickard@keele.ac.uk; Tel: 0044 (0)1782 733671; Fax: 0044

(0)1782 733516

G.T. Williams: E-mail: g.t.williams@keele.ac.uk; Tel: 0044 (0)1782 733032; Fax: 0044

(0)1782 733516

Running title: GAS5 and breast cancer 


\section{Abstract}

Purpose: The putative tumour suppressor and apoptosis-promoting gene, growth arrestspecific 5 (GAS5), encodes lncRNA and snoRNAs. Its expression is down-regulated in breast cancer, which adversely impacts patient prognosis. In this preclinical study, the consequences of decreased GAS5 expression for breast cancer cell survival following treatment with chemotherapeutic agents are addressed. In addition, functional responses of triple-negative breast cancer cells to GAS5 lncRNA are examined, and mTOR inhibition as a strategy to enhance cellular GAS5 levels is investigated. Methods: Breast cancer cell lines were transfected with either siRNA to GAS5 or with a plasmid encoding GAS5 lncRNA and the effects on breast cancer cell survival were determined. Cellular responses to mTOR inhibitors were evaluated by assaying culture growth and GAS5 transcript levels. Results: GAS5 silencing attenuated cell responses to apoptotic stimuli, including classical chemotherapeutic agents; the extent of cell death was directly proportional to cellular GAS5 levels. Imatinib action in contrast, was independent of GAS5. GAS5 lncRNA promoted the apoptosis of triple-negative and estrogen receptor-positive cells but only dual PI3K/mTOR inhibition was able to enhance GAS5 levels in all cell types. Conclusions: Reduced GAS5 expression attenuates apoptosis induction by classical chemotherapeutic agents in breast cancer cells, providing an explanation for the relationship between GAS5 expression and breast cancer patient prognosis. Clinically, this relationship may be circumvented by the use of GAS5independent drugs such as imatinib, or by restoration of GAS5 expression. The latter may be achieved by the use of a dual PI3K/mTOR inhibitor, to improve apoptotic responses to conventional chemotherapies. 
Keywords: GAS5, ncRNA, apoptosis, breast, cancer, chemotherapy.
Abbreviations:
A490
Absorbance at $490 \mathrm{~nm}$
$\mathrm{C}_{\mathrm{T}}$
Threshold cycle
EST
Expressed sequence tag
$5-\mathrm{FU}$
5-Fluorouracil
GAS5 Growth arrest-specific 5
HER2 Human epidermal growth factor receptor 2
lncRNA Long ncRNA
MCT Multiple comparison test
NC Negative control
ncRNA Non-coding RNA
NMD Nonsense-mediated decay
RT-qPCR Real time reverse transcription polymerase chain reaction
5'-TOP 5'-Terminal oligopyrimidine tract
TNBC Triple-negative breast cancer
UV-C Ultraviolet-C. 


\section{Introduction}

Long ncRNAs (size range: 0.2 - $100 \mathrm{~kb}$ ) are emerging as key regulators of fundamental cellular processes and are increasingly recognized as of importance in the pathogenesis, diagnosis and treatment of major cancers, including breast cancer [1-5]. Apart from ribosomal RNAs, lncRNAs comprise a plethora of mRNA-like transcripts (long intergenic ncRNAs, pseudogene-derived transcripts and sequences that are intronic or antisense to protein coding genes) $[1,6,7]$, which can act as signals, scaffolds, guides, decoys or tethers to modulate, for example, the maintenance of subcellular structures, chromatin modification and transcriptional/post-transcriptional regulation of gene expression [7, 8].

The lncRNA and small nucleolar RNA (snoRNA) host gene, growth arrest-specific 5 (GAS5), is of particular interest in breast cancer, since its expression is down-regulated in tumour tissue [9], and patient prognosis is related to GAS5 transcript levels [10]. GAS5 is a 5'-terminal oligopyrimidine tract (5'-TOP) gene, and comprises 12 exons which are alternatively spliced to yield two possible mature lncRNAs [11]. GAS5 intronic sequence additionally encodes ten distinct box C/D snoRNAs [11]; three of which (U44, U74 and U78) may serve as miRNA precursors [12]. Multiple other GAS5 expressed sequence tags (ESTs) have also been identified, many of which contain retained introns, indicating that posttranscriptional processing of GAS5 RNA is complex.

GAS5 transcripts accumulate in growth-arrested cells $[11,13]$ due to interplay between the mTOR pathway (through its regulation of translation of RNAs carrying the 5'-TOP sequence) and the nonsense-mediated decay (NMD) pathway (due to the GAS5 short reading frame) $[11,14]$. Thus, in actively growing cells, where mTOR activity is high, translation of the 
short reading frame is promoted, resulting in degradation of transcripts by the NMD pathway, and consequently low cellular GAS5 lncRNA levels. Suppression of cell growth and mTOR activity prevents the active translation of GAS5 transcripts and their consequent degradation by NMD, resulting in the accumulation of GAS5 lncRNA [11, 13, 14]. Direct inhibition of mTOR activity by rapamycin and rapalogues produces the predicted increase in cellular GAS5 lncRNA [11, 15, 16].

In breast and other cell types, GAS5 inhibits cell proliferation and/or stimulates apoptosis [9, 17-21], i.e., key determinants of cell survival that are often disrupted in cancer [22]. Indeed, elevated GAS5 expression inhibits human breast tumour growth in a xenograft mouse model [21], consistent with a tumour suppressor role for this gene. Moreover, the apoptosispromoting activity of GAS5 has implications for cancer therapies, since the action of many chemotherapeutic drugs ultimately depends on engagement of the cellular apoptotic machinery [23, 24]. However, the consequences of reduced GAS5 expression for chemotherapeutic drug action in breast cancer cells have not been examined to-date.

In this study we have focussed on the chemotherapeutic implications of reduced GAS5 expression in breast cancer. Firstly, we have investigated the hypothesis that GAS5 silencing impairs the responses of breast cancer cells to apoptotic stimuli. Secondly, we have examined whether functional responses to GAS5 remain intact in triple-negative breast cancer (TNBC) cells. Finally, we have investigated mTOR inhibition as a strategy to enhance cellular GAS5 levels in breast cancer cells and consequently to suppress cancer growth through the induction of apoptosis and/or cell cycle arrest. 


\section{Materials and methods}

\section{Material}

Cell lines were from ATCC-LGC Promochem (Teddington, UK). Cell culture materials and classical chemotherapeutic drugs were from Sigma-Aldrich Company Ltd (Gillingham, UK). Sources of other drugs were: rapamycin (Millipore, Watford, UK); temsirolimus and everolimus (LC Laboratories, Woburn, MA); BEZ235 and AZD8055 (Stratech Scientific, Newmarket, UK); and imatinib (mesylate) (Cayman Chemical, Ann Arbor, MI). TRIzol, reverse transcription reagents, TaqMan assays and Silencer Select siRNAs were from Life Technologies Ltd (Paisley, UK). SensiFast Probe Hi-ROX kit was from Bioline (London, UK), RQ1 RNase-free DNase and the MTS assay (CellTiter 96 AQueous One Solution Cell Proliferation Assay) were from Promega (Southampton, UK), RNAiFect was from Qiagen (Crawley, UK) and nucleofector solution V was from Lonza Biosciences (Verviers, Belgium).

\section{Methods \\ Cell culture}

The breast cancer cell lines MCF7, T-47D and MDA-MB-231 were generated from secondary stocks of cells which had been frozen down within two weeks receipt from the ATCC. Cells were cultured in R-10 medium (RPMI-1640 supplemented with 2 mM Lglutamine, $1 \mathrm{mM}$ sodium pyruvate, $10 \mathrm{mM}$ HEPES, $10 \%$ fetal bovine serum and $50 \mu \mathrm{g} / \mathrm{ml}$ gentamicin) at $37{ }^{\circ} \mathrm{C}$ in a humidified incubator with $5 \% \mathrm{CO}_{2}$. Cell lines were replaced with fresh stocks after a maximum culture period of two months. 


\section{RNA interference by siRNA}

Cells were transfected with Ambion Silencer Select siRNAs using RNAiFect reagent, according to a standard protocol [20]. Up to 4 different GAS5 siRNAs were employed, termed siRNAs \#1 - 4 (product codes/targeted exons are: n272334/exon 2; n272337/exon 8; n272340/exon 12 and n272331/exon 12, respectively); controls received negative control (NC) siRNA (code AM4611).

\section{Plasmid DNA transfection}

Plasmids were: pcDNA3/GAS5.O1 (encodes GAS5 O1 EST); pcDNA3/GAS5.AE (encodes mature GAS5 lncRNA); and pcDNA3 vector (for controls) [20]. Cells were nucleofected with plasmids ( $2 \mu \mathrm{g}$ per $2 \times 10^{6}$ cells in $0.1 \mathrm{ml}$ nucleofector solution $\mathrm{V}$ ) using programmes E014 and X-013 for MCF7 and MDA-MB-231, respectively, and cells were plated in $3 \mathrm{ml}$ R10 medium in 6-well plates.

\section{Induction of cell death and cell survival assays}

At $72 \mathrm{~h}$ post-siRNA transfection or at $20 \mathrm{~h}$ post-plasmid nucleofection, cells were trypsinized, sampled for RNA, then seeded $\left(0.8 \times 10^{5}\right.$ cells for siRNA-transfected cells; $1.6 \mathrm{x}$ $10^{5}$ cells for plasmid-transfected cells) into 12 -well plates. Ultraviolet-C (UV-C) irradiation was performed prior to plating [20]; doses were $40 \mathrm{~J} / \mathrm{m}^{2}$ for MCF7 and MDA-MB-231 cells, and $60 \mathrm{~J} / \mathrm{m}^{2}$ for T-47D cells; controls were mock-irradiated. For drug treatments, cells were cultured for $20 \mathrm{~h}$, before addition of 5-fluorouracil (5-FU; $175 \mu \mathrm{M})$, docetaxel (10 $\mu \mathrm{M})$, 
imatinib $(50 \mu \mathrm{M})$ or vehicle $(0.25 \%$ dimethyl sulphoxide). Cells were cultured for $48 \mathrm{~h}$ posttreatment, then adherent cells were trypsinized and combined with non-adherent cells for analysis of cell survival.

Apoptosis was routinely determined by assessment of nuclear morphology by fluorescence microscopy after staining with acridine orange $(25 \mu \mathrm{g} / \mathrm{ml})$; cells containing condensed or fragmented chromatin were scored as apoptotic. Cell viability was determined by counting of nigrosin blue $(0.1 \%(\mathrm{w} / \mathrm{v}))$ stained samples using a haemocytometer and light microscopy. For clonogenic assays, cells were re-plated in culture medium supplemented with $10 \%(\mathrm{v} / \mathrm{v})$ cell-conditioned medium in 6-well plates, cultured for 3 weeks, then the number of colonies was counted after staining with crystal violet.

\section{Assessment of mTOR inhibitor sensitivity}

Cells were plated in 96-well plates (500 cells in $0.1 \mathrm{ml} \mathrm{R} 10$ medium) and in 12-well plates (1.6 x $10^{5}$ cells in $0.8 \mathrm{ml} \mathrm{R} 10$ medium). After $4 \mathrm{~h}$, an equal volume of medium containing the appropriate drug or vehicle (final concentrations: $1 \mu \mathrm{M}$ rapamycin, $10 \mathrm{nM}$ everolimus, $10 \mathrm{nM}$ temsirolimus, $100 \mathrm{nM}$ BEZ235, $50 \mathrm{nM}$ AZD8055 or $0.1 \%$ dimethyl sulphoxide) was added. Experiments were terminated after a further $20 \mathrm{~h}$ (12-well plates; for GAS5 determination) or $70 \mathrm{~h}$ (96-well plates; for MTS assay). For the latter, sample absorbance readings at $490 \mathrm{~nm}$ (A490) were corrected for the appropriate medium plus drug blank values. 


\section{Effect of cell density-induced growth arrest on cellular GAS5 levels}

For low cell density, logarithmic phase cultures, cells were plated at $2 \times 10^{5}$ per well (6-well plate) then harvested after 24 h culture. For high cell density, stationary phase cultures, cells plated at $10 \times 10^{5}$ cells per well (6-well plate) then harvested after $96 \mathrm{~h}$ culture.

\section{Real time $R T-P C R(R T-q P C R)$}

TaqMan Gene Expression Assays (assay codes Hs99999901_m1 for 18S and Hs03464472_m1 for GAS5) were employed with cDNA prepared by random hexamer priming, as described previously [20]. Assays ( $25 \mu \mathrm{l})$ contained $10 \mathrm{ng}$ sample cDNA or $0.2-$ 60 ng standard cDNA (prepared from MCF7 cells). Input amounts of samples were calculated from their respective threshold cycle $\left(\mathrm{C}_{\mathrm{T}}\right)$ values, using standard curves generated with each assay. Data were expressed relative to $18 \mathrm{~S}$ rRNA.

\section{Statistical analyses}

Data are presented as the mean \pm SEM; the number of observations (n) refers to different transfected samples (each from separate cultures) or separate cultures. Data analysis was either by an unpaired Student's $t$-test (when comparing two groups only) or by one-way analysis of variance with either Bonferroni's multiple comparison test (MCT) or Dunnett's MCT (when comparing multiple groups versus a single group), as indicated. Homogeneity of variance was checked by Bartlett's test and, where necessary, data were transformed (log or square root) prior to analysis. The relationship between survival parameters and GAS5 levels in cells was analyzed by linear regression. Statistical analyses were performed using GraphPad Prism v4.03. 


\section{Results \\ GAS5 silencing attenuates apoptosis induction in breast cancer cells}

To examine the effects of reduced GAS5 expression on breast cancer cell survival, GAS5 siRNAs were employed to silence endogenous GAS5 expression in two cell lines, MCF7 and T-47D; a range of siRNAs were employed to reduce the likelihood of 'off-target' effects. The influence of GAS5 silencing on cell survival was examined under basal conditions and after apoptosis induction by a range of stimuli.

In MCF7 cells, GAS5 siRNAs reduced GAS5 transcript levels by upto one third of control levels (Fig. 1a). This had no statistically significant effect on basal apoptosis (Fig. 1b), shortterm viability (Fig. 1d), viable cell number (Fig. 1f) or clonogenic activity (Fig. 1h), as judged from mock-irradiated cells. However, GAS5 knockdown attenuated apoptosis induction by UV-C irradiation (Fig. 1c) and the consequent reduction in culture viability (Fig. 1e) and clonogenic activity (Fig. 1i). Growth arrest due to UV-C treatment appeared less markedly affected however, as judged from viable cell counts (Fig. 1g).

Consistent with these observations, GAS5 knockdown in T-47D cells (Fig. 2a) diminished apoptosis induction by UV-C irradiation (Fig. 2c), as well as the associated losses in culture viability (Fig. 2e) and clonogenic activity (Fig. 2i); less robust effects on UV-C-induced growth arrest were also noted for this cell line (Fig. 2g). Basal apoptosis was also reduced by GAS5 silencing in T-47D cells (Fig. 2b), in contrast to findings in MCF7 cells (Fig. 1b). This 
was associated with increased culture viability (Fig. 2d), but basal clonogenic activity was unaffected (Fig. 2h).

These findings were confirmed (Figs. $3 a \& b$ ) in control experiments examining the effects of GAS5 silencing on chemotherapeutic drug action. GAS5 silencing diminished docetaxelinduced apoptosis and the associated loss of culture viability in both MCF7 (Fig. 3c) and T47D cells (Fig. 3d). Similar effects were observed regarding 5-FU action in MCF7 (Fig. 3e) and T-47D (Fig. 3f) cells, whereas, imatinib action was unaffected by GAS5 silencing (Figs. $3 g \& h)$.

Breast cancer cell survival is related to cellular GAS5 levels

If impaired responses to chemotherapeutic drugs underlie the clinical relationship between patient survival and breast cancer GAS5 levels [10], then parameters of breast cancer cell survival should show quantitative relationships with cellular GAS5 levels. Regression analysis was therefore performed on data from the GAS5 silencing experiments; cellular GAS5 levels were expressed relative to those in negative control siRNA-treated cultures to facilitate comparisons between the two cell lines.

Under basal conditions, apoptosis and viability were related to cellular GAS5 levels in T-47D cells (Fig. 4b) but not in MCF7 cells (Fig. 4a). Upon treatment with either UV-C irradiation (Figs. 4c \& d), docetaxel (Figs, 4e \& f) or 5-FU (Figs. 4g \& h), consistent and statistically significant relationships were observed for MCF7 and T-47D cells; apoptosis was characterized by a direct relationship — and viability by a corresponding inverse 
relationship —with cellular GAS5 levels (Figs. 4c - 4h). Parameters of cell survival after imatinib treatment were unrelated to cellular GAS5 levels in both cell lines (data not shown).

\title{
GAS5 IncRNA is sufficient to induce apoptosis in MCF7 cells
}

The transfection of breast cancer cells with GAS5 ESTs promotes apoptosis [9], but it is unclear whether mature GAS5 lncRNA is sufficient to mediate this action, as all the effective GAS5 ESTs contained retained snoRNAs. Therefore, the cell death-promoting activities of mature GAS5 lncRNA (i.e., exons 1 - 12 only) and the GAS5-O1 EST (comprises snoRNA U74, 3' sequence of the first intron and exons 2 - 12) were compared in MCF7 cells.

\begin{abstract}
Transfection of MCF7 cells with each GAS5 construct increased cellular GAS5 levels to a similar extent (Fig. 5a). As expected [9], the GAS5-O1 construct increased the proportion of apoptotic cells and decreased culture viability (Fig. 5b) at $24 \mathrm{~h}$ post-nucleofection; the GAS5AE construct, which encodes mature lncRNA, produced a similar quantitative response (Fig. 5b). Likewise, GAS5-O1 and GAS5-AE constructs stimulated UV-C-induced apoptosis and loss of culture viability (Fig. 5c) to a similar extent. Thus, mature GAS5 lncRNA is sufficient to promote apoptosis in MCF7 cells.
\end{abstract}

\section{GAS5 IncRNA also induces apoptosis in triple-negative MDA-MB-231 cells}

Endogenous levels of GAS5 transcripts are reduced in the TNBC cell line, MDA-MB-231, relative to estrogen receptor-positive cell lines $[9,21]$. To examine if TNBC cells retain sensitivity to GAS5 lncRNA, parameters of cell survival were assessed following transfection 
of MDA-MB-231 cells with the plasmid encoding mature GAS5 lncRNA. Increased GAS5 levels (Fig. 6a) were associated with increased basal apoptosis and reduced culture viability (Fig. 6b) from $24 \mathrm{~h}$ post-nucleofection, and also enhanced the death of MDA-MB-231 cells upon UV-C-irradiation (Fig. 6c). Thus, triple-negative MDA-MB-231 cells are sensitive to GAS5 lncRNA, as for MCF7 cells.

mTOR inhibition modulates GAS5 expression in breast cancer cell lines

Clinically, the use of mTOR inhibitors may offer a simple method to enhance cellular GAS5 levels in order to promote the death of breast cancer cells. Therefore, we initially examined the effects of rapamycin and related first generation mTOR inhibitors on breast cancer cell lines. These agents inhibited the growth of all cell lines by between $c a$. $20-50 \%$; the extent of growth inhibition was similar for MCF7 and T-47D cells, but was noticeably smaller for MDA-MB-231 cells, irrespective of the applied rapalogue (Fig. 7a). Cellular GAS5 levels were enhanced by $>50 \%(P<0.05$; one-way ANOVA and Bonferroni's MCT) by rapalogue treatment of MCF7 and T-47D cells, whereas they were unchanged in MDA-MB-231 cells (Fig. 7a). In view of this resistance of MDA-MB-231 cells to first generation mTOR inhibitors (which act selectively on mTORC1), we next examined the effects of inhibitors with a broader specificity, i.e. the dual mTORC1/mTORC2 inhibitor, AZD8055, and the dual PI3K/mTOR inhibitor, BEZ235. The pattern of cell line response to AZD8055 was similar to that of rapalogues, whereas BEZ235 markedly inhibited growth and robustly elevated GAS5 levels in all cell lines (Fig. 7b). 


\section{Discussion}

The development of targeted therapies has revolutionised the treatment of hormone receptorpositive and human epidermal growth factor receptor 2 (HER2)-positive breast cancer, but resistance to these therapies remains problematic $[25,26]$. Furthermore, there currently exists no approved targeted therapy for TNBC (lacks estrogen receptor, progesterone receptor and HER2 amplification), which frequently exhibits highly malignant behaviour and resistance to conventional chemotherapies [27]. The identification of novel therapeutic targets for multiple breast cancer subtypes is therefore important, and lncRNAs may offer new opportunities in this regard, given their emerging roles as regulators of fundamental biological processes [15]. Indeed, GAS5 is already of particular interest in relation to breast cancer, since its expression is down-regulated in tumour tissue [9], and patient prognosis is significantly related to GAS5 transcript levels [10]. Current findings in preclinical models demonstrate here, for the first time, that breast cancer cell responses to several apoptotic stimuli are quantitatively related to cellular GAS5 levels, suggesting a potential functional basis for the latter clinically important relationship. The cytotoxic action of certain drugs, such as imatinib, is shown to be GAS5-independent, thereby suggesting a way to bypass the 
relationship to improve patient outcomes. Importantly, a possible therapeutic role for GAS5 lncRNA in TNBC is identified and, in this regard, dual PI3K/mTOR inhibition is demonstrated to be effective in increasing GAS5 levels in such cells.

\begin{abstract}
Although functional studies have previously reported that GAS5 transcripts exert apoptosispromoting effects in breast cancer cells and in a range of other cell types [9, 15, 18-21], the consequences of reduced GAS5 expression for breast cancer cell survival have not been addressed. Here we demonstrate that reductions in GAS5 expression of $c a .50-70 \%$ in MCF7 and T-47D cells are consistently associated with attenuated cell death in response to a range of apoptosis-inducing agents (UV-C irradiation, 5-FU and docetaxel). Crucially, as in recent experiments with prostate cancer cells [20], both the extent of apoptosis induction and the associated loss of culture viability are quantitatively related to the extent of GAS5 silencing. Thus, even small reductions in endogenous GAS5 expression may adversely impact upon the responses of breast cancer cells to certain death-inducing stimuli, including conventional chemotherapeutic agents, and this resistance to therapy may explain why breast cancer patient survival is related to tumour GAS5 levels [10].
\end{abstract}

Imatinib, which provides targeted therapy through inhibition of receptor and non-receptor tyrosine kinases (e.g., PDGF receptors, c-kit, c-Abl and Arg) in contrast, efficiently induced apoptosis in both MCF7 and T-47D cells, irrespective of cellular GAS5 levels. Thus GAS5 selectively modulates the action of chemotherapeutic agents, perhaps related to their differing mechanisms of engagement of the apoptotic machinery, as suggested by the additive or synergistic nature of imatinib action with a range of conventional chemotherapeutic agents [28-30]. From a therapeutic perspective, the use of GAS5-independent drugs may offer an 
improved strategy for breast cancer patients with reduced GAS5 expression, albeit further work is required to identify additional chemotherapeutic agents which act in a GAS5independent manner in breast cancer cells.

An alternative approach may be to enhance cellular GAS5 levels prior to, or concomitant with, the administration of conventional chemotherapies, in order to improve cytotoxic drug action. Current findings confirm that GAS5 lncRNA (rather than GAS5-derived snoRNA sequence) is sufficient for apoptosis-promoting activity, and further demonstrate that GAS5 lncRNA is active in the TNBC cell line, MDA-MB-231, which exhibits lower endogenous GAS5 levels than estrogen receptor-positive cell lines. Consequently, the proposed approach may be beneficial in TNBC, the treatment of which remains especially challenging [27]. Such a therapeutic goal could be achieved by a direct approach, involving, for example, gene therapy with vectors encoding GAS5 lncRNA, but the clinical application of such therapies in general, remains a long term prospect. Since a conventional pharmacological approach would be preferable in the short term, we focussed here on the mTOR pathway, which is involved in the physiological regulation of cellular GAS5 levels $[11,14]$. Only the dual PI3K/mTOR inhibitor, BEZ235, elevated GAS5 levels in all cell lines.

The reasons for the resistance of GAS5 transcript levels to mTOR inhibition in MDA-MB231 cells is unknown. This cell line also failed to increase GAS5 transcript levels upon cell density-induced growth arrest, suggesting a defect in the physiological mechanism of mTORmediated regulation of GAS5. Mutation of the 5'-TOP sequence can be excluded however, since the sequence of GAS5 exon 1 (contains the 5'-TOP) in MDA-MB-231 cells is identical to that of the NCBI Reference Sequence, NR_002578.2 (data not shown). The mTOR 


\section{Conclusions}

The extent of breast cancer cell death consequent upon exposure to certain chemotherapeutic drugs and other apoptotic stimuli is directly related to cellular GAS5 levels, implicating regulation of apoptosis as the functional role that links GAS5 expression levels with patient survival. The use of novel targeted therapies which act independently of GAS5, or combination therapies comprising conventional chemotherapeutics coupled with agents to enhance cellular GAS5 lncRNA levels, in breast tumours could prove beneficial in improving patient outcomes. In this regard, a wide range of mTOR inhibitors may prove useful in patients with receptor-positive disease, whereas treatment options may be limited to dual $\mathrm{PI} 3 \mathrm{~K} / \mathrm{mTOR}$ inhibitors in TNBC patients. Findings here in breast cancer cell lines may be relevant to the therapy of a wide range of other cancers, including head and neck squamous cell carcinoma [10], glioblastoma multiforme [35], renal clear cell carcinoma [36], bladder 
cancer [37], pancreatic cancer [38] and non-small-cell lung cancer [39], all of which are characterized by deficient GAS5 expression.

\section{Acknowledgements}

This work was supported by a grant from the Breast Cancer Campaign, which is gratefully acknowledged.

\section{Conflicts of interest}

The authors declare that they have no conflicts of interest. 


\section{References}

1. Gibb EA, Brown CJ, Lam WL (2011) The functional role of long non-coding RNA in human carcinomas. Mol Cancer 10:38

2. Gutschner T, Diederichs S (2012) The hallmarks of cancer: a long non-coding RNA point of view. RNA Biol 9:703-719

3. Shore AN, Herschkowitz JI, Rosen JM (2012) Noncoding RNAs involved in mammary gland development and tumorigenesis: there's a long way to go. J Mammary Gland Biol Neoplasia 17:43-58

4. Spizzo R, Almeida MI, Colombatti A, Calin GA (2012) Long non-coding RNAs and cancer: a new frontier of translational research? Oncogene 31:4577-4587

5. Cheetham SW, Gruhl F, Mattick JS, Dinger ME (2013) Long noncoding RNAs and the genetics of cancer. Br J Cancer 108:2419-2425

6. Sana J, Faltejskova P, Svoboda M, Slaby O (2012) Novel classes of non-coding RNAs and cancer. J Transl Med 10:103

7. Kung JT, Colognori D, Lee JT (2013) Long noncoding RNAs: past, present, and future. Genetics 193:651-669

8. Wang KC, Chang HY (2011) Molecular mechanisms of long noncoding RNAs. Mol Cell 43:904-914

9. Mourtada-Maarabouni M, Pickard MR, Hedge VL, Farzaneh F, Williams GT (2009)

GAS5, a non-protein-coding RNA, controls apoptosis and is downregulated in breast cancer. Oncogene 28:195-208 
10. Gee HE, Buffa FM, Camps C, Ramachandran A, Leek R, Taylor M, Patil M, Sheldon H, commonly used for microRNA normalisation correlate with tumour pathology and prognosis. Br J Cancer 104:1168-1177

11. Smith CM, Steitz JA (1998) Classification of gas5 as a multi-small-nucleolar-RNA (snoRNA) host gene and a member of the 5'-terminal oligopyrimidine gene family reveals common features of snoRNA host genes. Mol Cell Biol 18:6897-6909

12. Brameier M, Herwig A, Reinhardt R, Walter L, Gruber J (2011) Human box C/D snoRNAs with miRNA like functions: expanding the range of regulatory RNAs. Nucleic Acids Res 39:675-686

13. Schneider C, King RM, Philipson L (1988) Genes specifically expressed at growth arrest of mammalian cells. Cell 54:787-793

14. Williams GT, Farzaneh F (2012) Are snoRNAs and snoRNA host genes new players in cancer? Nat Rev Cancer 12:84-88

15. Mourtada-Maarabouni M, Hasan AM, Farzaneh F, Williams GT (2010) Inhibition of human T-cell proliferation by mammalian target of rapamycin (mTOR) antagonists requires noncoding RNA growth-arrest-specific transcript 5 (GAS5). Mol Pharmacol 78:19-28

16. Williams GT, Mourtada-Maarabouni M, Farzaneh F (2011) A critical role for non-coding RNA GAS5 in growth arrest and rapamycin inhibition in human T-lymphocytes. Biochem Soc Trans 39:482-486

17. Williams GT, Hughes JP, Stoneman V, Anderson CL, McCarthy NJ, MourtadaMaarabouni M, Pickard M, Hedge VL, Trayner I, Farzaneh F (2006) Isolation of genes controlling apoptosis through their effects on cell survival. Gene Ther Mol Biol 10B:255-262 
18. Mourtada-Maarabouni, M, Hedge VL, Kirkham L, Farzaneh F, Williams GT (2008)

Growth arrest in human T-cells is controlled by the non-coding RNA growth-arrest-specific transcript 5 (GAS5). J Cell Sci 121:939-946

19. Kino T, Hurt DE, Ichijo T, Nader N, Chrousos GP (2010) Noncoding RNA gas5 is a growth arrest- and starvation-associated repressor of the glucocorticoid receptor. Sci Signal 3:ra8

20. Pickard MR, Mourtada-Maarabouni M, Williams GT (2013) Long non-coding RNA GAS5 regulates apoptosis in prostate cancer cell lines. Biochim Biophys Acta 1832:16131623

21. Zhang Z, Zhu Z, Watabe K, Zhang X, Bai C, Xu M, Wu F, Mo YY (2013) Negative regulation of lncRNA GAS5 by miR-21. Cell Death Differ 20:1558-1568

22. Hanahan D, Weinberg RA (2011) Hallmarks of cancer: the next generation. Cell 144:646674

23. McKenzie S, Kyprianou N (2006) Apoptosis evasion: the role of survival pathways in prostate cancer progression and therapeutic resistance. J Cell Biochem 97:18-32

24. Indran IR, Tufo G, Pervaiz S, Brenner C (2011) Recent advances in apoptosis, mitochondria and drug resistance in cancer cells. Biochim Biophys Acta 1807:735-745

25. Mohamed A, Krajewski K, Cakar B, Ma CX (2013) Targeted therapy for breast cancer. Am J Pathol 183:1096-1112

26. Palmieri C, Patten DK, Januszewski A, Zucchini G, Howell SJ (2014) Breast cancer: Current and future endocrine therapies. Mol Cell Endocrinol 382:695-723 
27. Engebraaten O, Vollan HK, Børresen-Dale AL (2013) Triple-negative breast cancer and the need for new therapeutic targets. Am J Pathol 183:1064-1074

28. Kano Y, Akutsu M, Tsunoda S, Mano H, Sato Y, Honma Y, Furukawa Y (2001) In vitro cytotoxic effects of a tyrosine kinase inhibitor STI571 in combination with commonly used antileukemic agents. Blood 97:1999-2007

29. Sims JT, Ganguly S, Fiore LS, Holler CJ, Park ES, Plattner R (2009) STI571 sensitizes breast cancer cells to 5-fluorouracil, cisplatin and camptothecin in a cell type-specific manner. Biochem Pharmacol 78:249-260

30. Weigel MT, Dahmke L, Schem C, Bauerschlag DO, Weber K, Niehoff P, Bauer M, Strauss A, Jonat W, Maass N, Mundhenke C (2010) In vitro effects of imatinib mesylate on radiosensitivity and chemosensitivity of breast cancer cells. BMC Cancer 10:412

31. Chen Y, Zheng Y, Foster DA (2003) Phospholipase D confers rapamycin resistance in human breast cancer cells. Oncogene 22:3937-3942

32. Chen G, Yang N, Wang X, Zheng SY, Chen Y, Tong LJ, Li YX, Meng LH, Ding J (2010) Identification of $\mathrm{p} 27 / \mathrm{KIP} 1$ expression level as a candidate biomarker of response to rapalogs therapy in human cancer. J Mol Med (Berl) 88:941-952

33. Noh WC, Mondesire WH, Peng J, Jian W, Zhang H, Dong J, Mills GB, Hung MC, MericBernstam F (2004) Determinants of rapamycin sensitivity in breast cancer cells. Clin Cancer Res 10:1013-1023

34. Wong SW, Tiong KH, Kong WY, Yue YC, Chua CH, Lim JY, Lee CY, Quah SI, Fow C, Chung C, So I, Tan BS, Choo HL, Rosli R, Cheong SK, Leong CO (2011) Rapamycin synergizes cisplatin sensitivity in basal-like breast cancer cells through up-regulation of p73. Breast Cancer Res Treat 128:301-313 
35. Lee J, Kotliarova S, Kotliarov Y, Li A, Su Q, Donin NM, Pastorino S, Purow BW, Christopher N, Zhang W, Park JK, Fine HA (2006) Tumor stem cells derived from glioblastomas cultured in bFGF and EGF more closely mirror the phenotype and genotype of primary tumors than do serum-cultured cell lines. Cancer Cell 9:391-403

36. Qiao HP, Gao WS, Huo JX, Yang ZS (2013) Long non-coding RNA GAS5 functions as a tumor suppressor in renal cell carcinoma. Asian Pac J Cancer Prev 14:1077-1082

37. Liu Z, Wang W, Jiang J, Bao E, Xu D, Zeng Y, Tao L, Qiu J (2013) Downregulation of GAS5 promotes bladder cancer cell proliferation, partly by regulating CDK6. PLoS One 8:e73991

38. Lu X, Fang Y, Wang Z, Xie J, Zhan Q, Deng X, Chen H, Jin J, Peng C, Li H, Shen B (2013) Downregulation of gas5 increases pancreatic cancer cell proliferation by regulating CDK6. Cell Tissue Res 354:891-896

39. Shi X, Sun M, Liu H, Yao Y, Kong R, Chen F, Song Y (2013) A critical role for the long non-coding RNA GAS5 in proliferation and apoptosis in non-small-cell lung cancer. Mol Carcinog. doi: 10.1002/mc.22120 [Epub ahead of print]. 


\section{Figure legends}

Fig. 1 Effect of GAS5 siRNA on basal survival and UV-C-induced cell death in MCF7 cells. MCF7 cells ( $n=5$ cultures) were transfected with the indicated GAS5 siRNA or negative control (NC) siRNA and harvested at $72 \mathrm{~h}$ post-transfection. Cells were treated $\pm \mathrm{UV}-\mathrm{C}$ irradiation and replated for assessment of cell survival after a further $48 \mathrm{~h}$. RT-qPCR analysis confirmed decreased cellular GAS5 levels at $72 \mathrm{~h}$ post-transfection in cells treated with GAS5 siRNAs (a). Silencing of GAS5 has no statistically significant effect on basal apoptosis in MCF7 cells (b), whereas it attenuates UV-C-induced apoptosis (c). Correspondingly, viability is not significantly affected in control cells (d), but it is enhanced in UV-C-treated cells (e). Viable cell numbers are not significantly affected in both control (f) and UV-Ctreated (g) cells. Clonogenic activity is also unaffected in control cells (h) but it is enhanced in UV-C-treated cells (i). ${ }^{*} P<0.05 \& * * P<0.01$ versus cells transfected with NC siRNA (one-way ANOVA and Dunnett's MCT) 
Fig. 2 Effect of GAS5 siRNA on basal survival and UV-C-induced cell death in T-47D cells. T-47D cells ( $\mathrm{n}=4$ cultures) were transfected with the indicated GAS5 siRNA or negative control (NC) siRNA and harvested at $72 \mathrm{~h}$ post-transfection. Cells were treated $\pm \mathrm{UV}-\mathrm{C}$ irradiation and replated for assessment of cell survival after a further $48 \mathrm{~h}$. RT-qPCR analysis confirmed decreased cellular GAS5 levels at $72 \mathrm{~h}$ post-transfection in cells treated with GAS5 siRNAs (a). Silencing of GAS5 reduces both basal (b) and UV-C-induced apoptosis (c). Correspondingly, viability is enhanced in control (d) and UV-C-treated cells (e). Viable cell numbers are not significantly affected in both control (f) and UV-C-treated (g) cells.

Clonogenic activity is unaffected in control cells (h) but it is enhanced in UV-C-treated cells (i). ${ }^{*} P<0.05, * * P<0.01 \& * * * P<0.001$ versus cells transfected with NC siRNA (one-way ANOVA and Dunnett's MCT) 
Fig. 3 Effect of GAS5 silencing on chemotherapeutic drug-induced death of breast cancer cell lines. MCF7 and T-47D cells $(n=5$ cultures) were transfected with the indicated GAS5 siRNA or negative control (NC) siRNA and, after $72 \mathrm{~h}$, exposed to chemotherapeutic agents or vehicle for $48 \mathrm{~h}$. For all figure parts, apoptosis is displayed in the left-hand panel and culture viability in the right-hand panel. For vehicle controls, GAS5 silencing had negligible effects overall on apoptosis and culture viability in MCF7 cells (a), whereas it reduced apoptosis and increased culture viability in T-47D cells (b). For docetaxel treatment, prior GAS5 silencing resulted in consistent and corresponding effects on apoptosis and culture viability in both MCF7 (c) and T-47D cells (d). Similar effects were observed for 5-FU treatment of MCF7 (f) and T-47D (g) cells, whereas induction of cell death by imatinib was unaffected by GAS5 silencing in both cell lines (h and $\mathbf{i}$, respectively). ${ }^{*} P<0.05 \& * * P<$ 0.01 versus cells transfected with NC siRNA (one-way ANOVA and Dunnett's MCT) 
Fig. 4 Parameters of cell survival are related to cellular GAS5 levels in breast cancer cell lines. Regression analysis was performed for data from Figs. 1 - 3 against cellular GAS5 levels normalized relative to control (NC siRNA) values; for all figure parts, apoptosis is displayed in the left-hand panel and culture viability in the right-hand panel. In the absence of any exogenous apoptotic stimulus, apoptosis and culture viability were unrelated to GAS5 levels in MCF7 cells (a), whereas apoptosis was directly related to-and culture viability was inversely related to - cellular GAS5 levels in T-47D cells (b). Apoptosis and culture viability were also related to GAS5 levels in both MCF7 and T-47D cells upon exposure to the apoptotic stimuli: UV-C irradiation (c \& d); docetaxel (e \& f); and 5-FU (g \& h) 
Fig. 5 Comparison of the effects of GAS5 ncRNA constructs on the survival of MCF7 cells, both basally and after UV-C-induced apoptosis. Cells $(n=4)$ were transfected with GAS5 constructs corresponding to mature lncRNA (exons 1 - 12; AE), the GAS5.O1 EST (snoRNA U74 plus exons 2 - 12; O1), or empty pcDNA3 vector (V) as control. After $24 \mathrm{~h}$, cells were treated \pm UV-C irradiation then re-sampled after a further 48 h. a) Cellular GAS5 levels at 24 h post-transfection are increased to a similar extent by GAS5 O1 and AE constructs. b) At 24 $\mathrm{h}$ post-transfection, the two GAS5 constructs result in similar increases in basal apoptosis (left-hand panel) and similar decreases in basal culture viability (right-hand panel). c) The two GAS5 constructs exhibit similar potency in enhancing both UV-C-induced apoptosis (left-hand panel) and the associated loss in culture viability (right-hand panel). $* P<0.05 \&$ $* * * P<0.001$ versus cells transfected with pcDNA3 alone (one-way ANOVA and Bonferroni's MCT) 
Fig. 6 GAS5 lncRNA is pro-apoptotic in MDA-MB-231 cells. Cells $(n=4)$ were transfected with a construct encoding mature lncRNA (AE) or empty pcDNA3 vector (V) as control and, after $24 \mathrm{~h}$, cells were treated $\pm \mathrm{UV}-\mathrm{C}$ irradiation, then re-sampled after a further $48 \mathrm{~h}$. a) Cellular GAS5 levels at $24 \mathrm{~h}$ post-transfection are increased by the GAS5 AE construct. b) GAS5 lncRNA increases basal apoptosis (left-hand panel) and reduces culture viability (right-hand panel) at $24 \mathrm{~h}$ post-transfection. c) GAS5 lncRNA increases UV-C-induced apoptosis (left-hand panel) and the associated loss of culture viability. $* P<0.05 \& * * * P<$ 0.001 versus cells transfected with pcDNA3 alone (Student's $t$-test [a \& b] or one-way ANOVA and Bonferrroni's MCT [c]) 
Fig. 7 Effects of pharmacological and physiological inhibitors of mTOR activity in breast cancer cell lines. a) Effect of rapamycin $(1 \mu \mathrm{M}$; R), everolimus (10 nM; E) and temsirolimus $(10 \mathrm{nM} ; \mathrm{T})$ on culture growth (at $70 \mathrm{~h}$; left-hand panel) and GAS5 levels (at $20 \mathrm{~h}$; right-hand panel). Data are expressed relative to the vehicle control; $* P<0.05$ and $* * P<0.01$ versus MDA-MB-231 cells (one-way ANOVA and Bonferrroni's MCT; $n=4$ cultures). b) Effect of AZD8055 (50 nM) and BEZ235 (100 nM) on culture growth (at $70 \mathrm{~h}$; left-hand panel) and GAS5 levels (at $20 \mathrm{~h}$; right-hand panel). Data are expressed relative to the vehicle control; ** $P<0.01$ and $* * * P<0.001$ versus MDA-MB-231 cells and ${ }^{++} P<0.01$ versus MCF7 cells (one-way ANOVA and Bonferrroni's MCT; $n=4$ cultures). c) Effect of cell density-induced growth arrest on cellular GAS5 levels; cells were harvested at logarithmic (log) and stationary (stat) phases of growth; $* * P<0.01$ and $* * * P<0.001$ versus logarithmic phase cultures (one-way ANOVA and Bonferrroni's MCT; $\mathrm{n}=4$ cultures) 
Figure 1

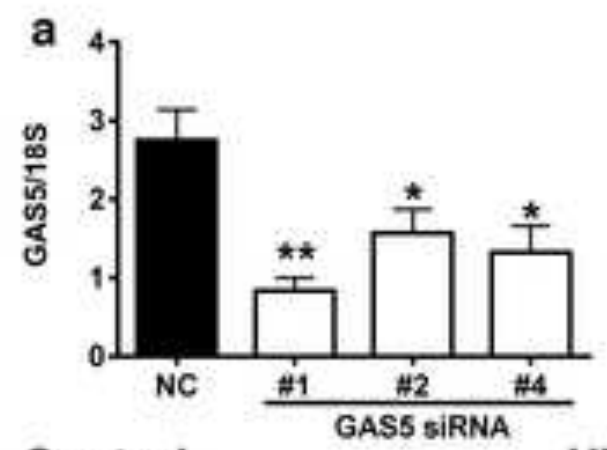

Control

b

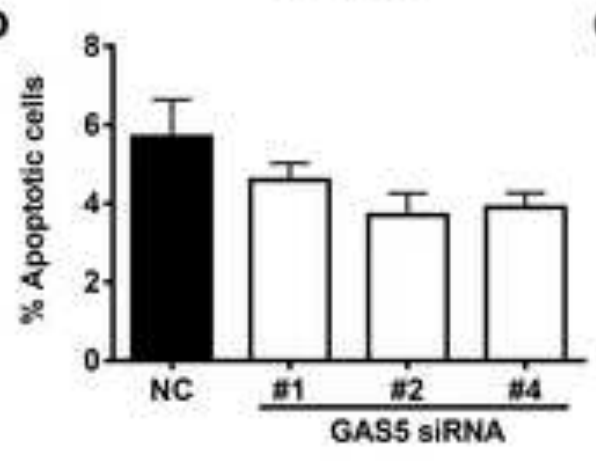

d
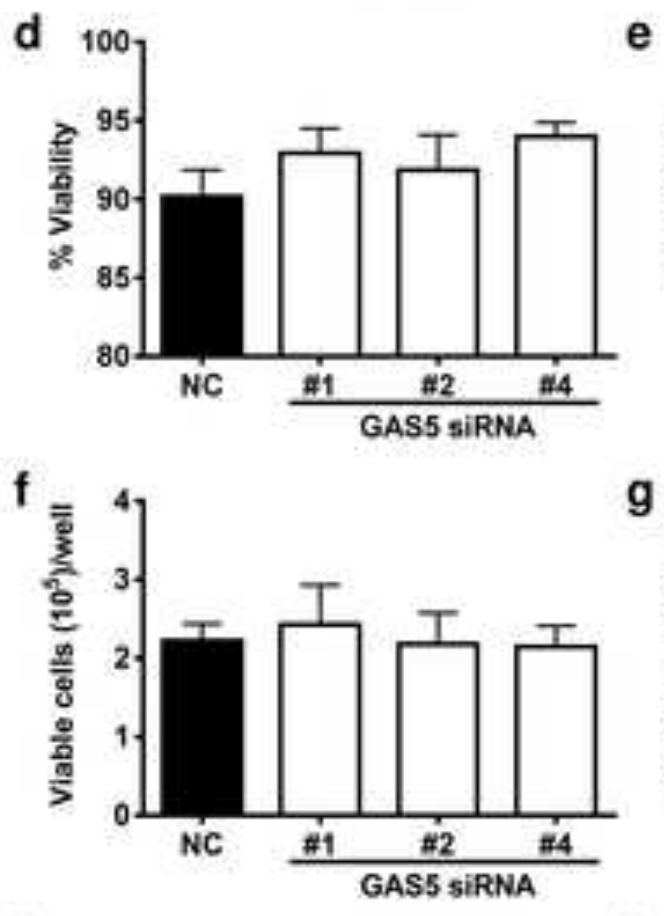

h

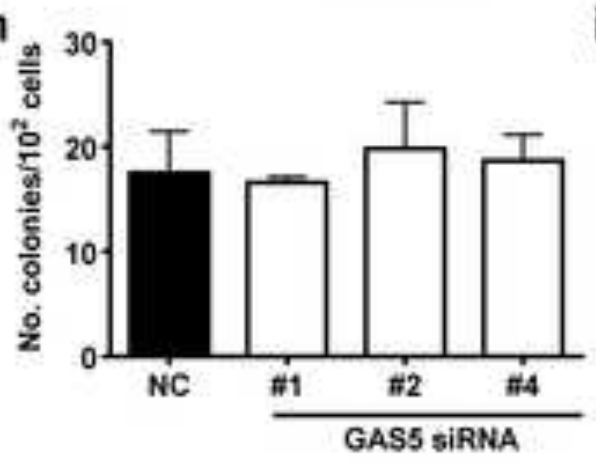

c

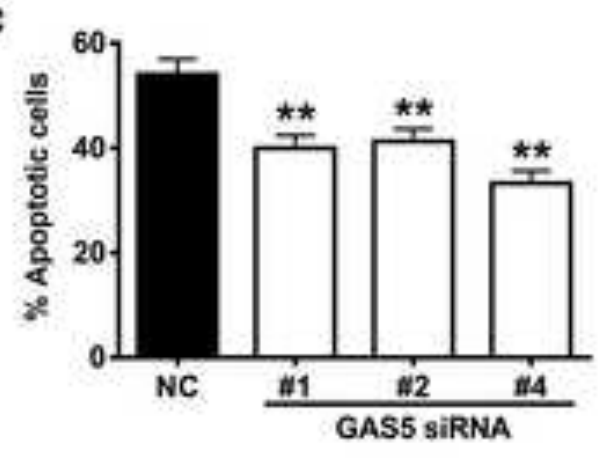

e
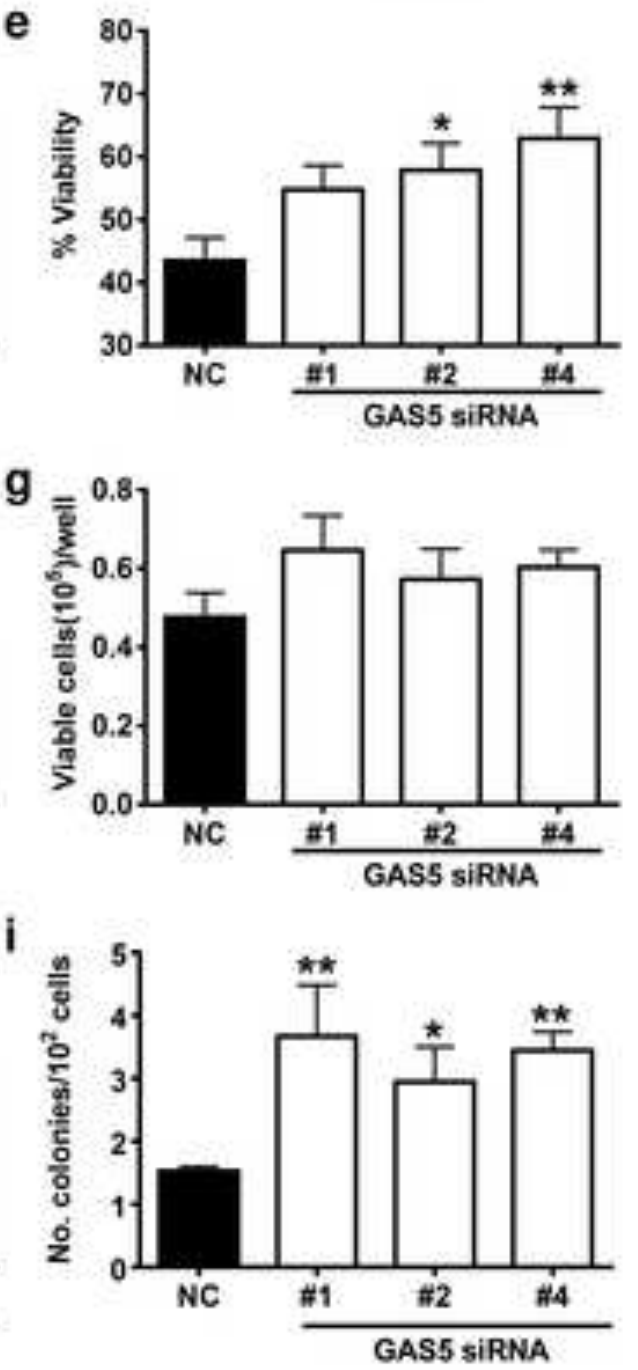
Figure 2

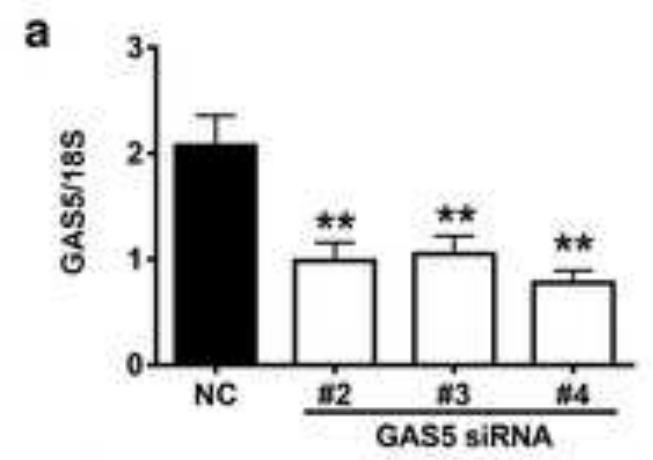

\section{Control}

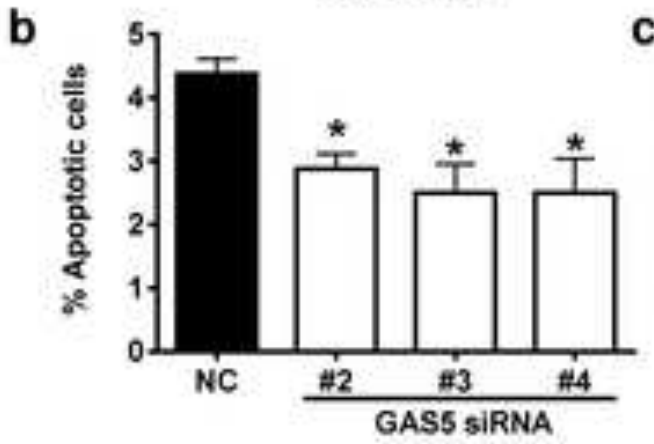

UVC-Irradiated

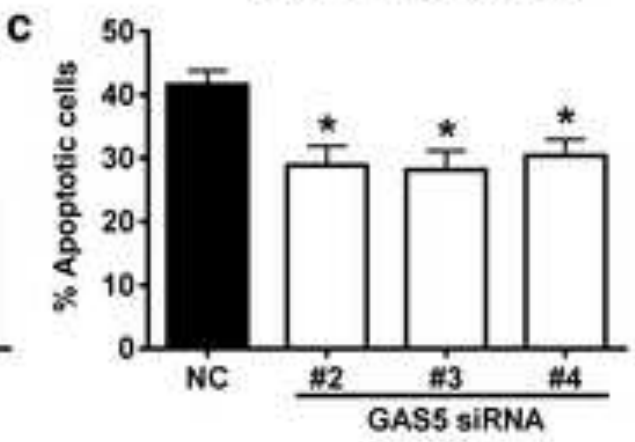

d
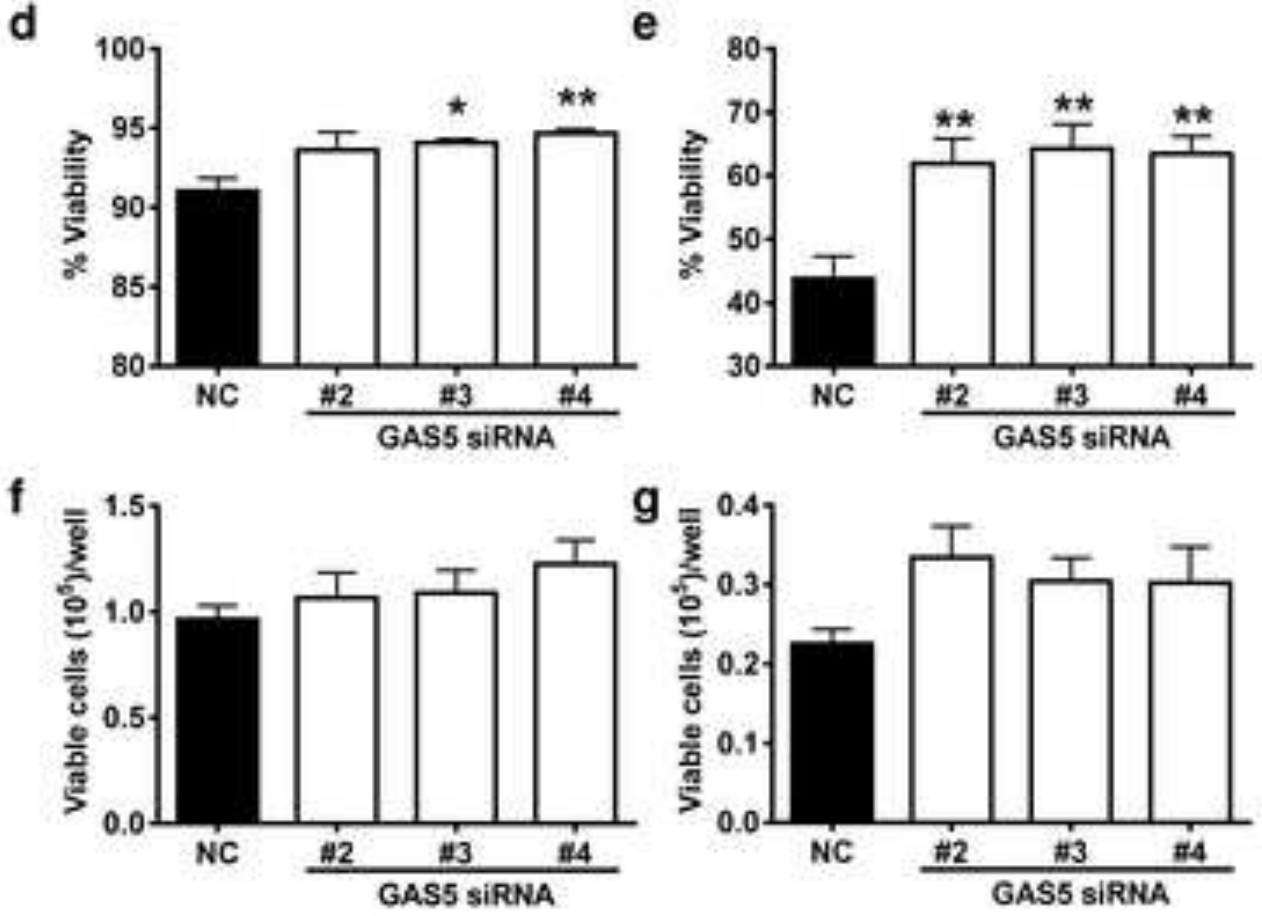

h

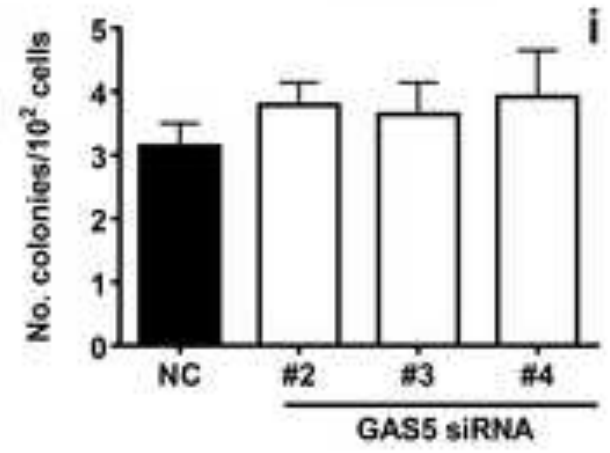

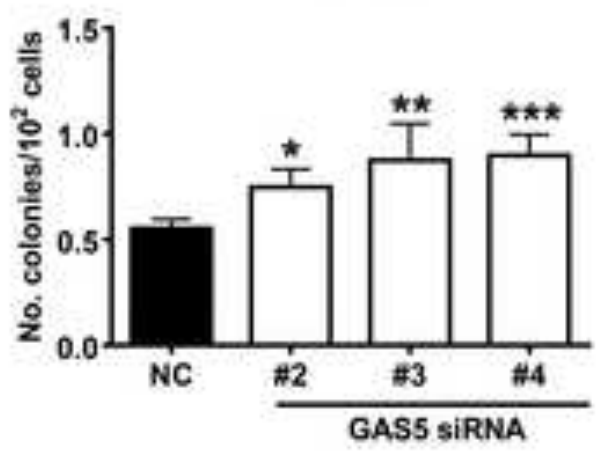



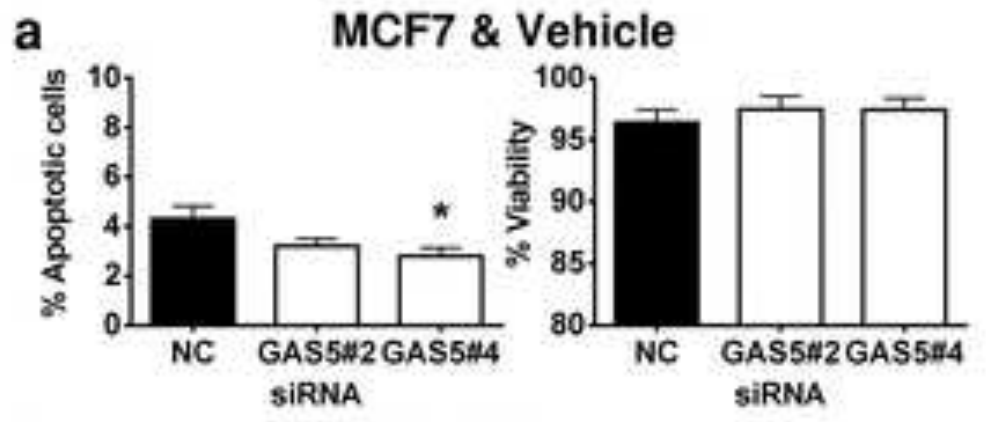

C
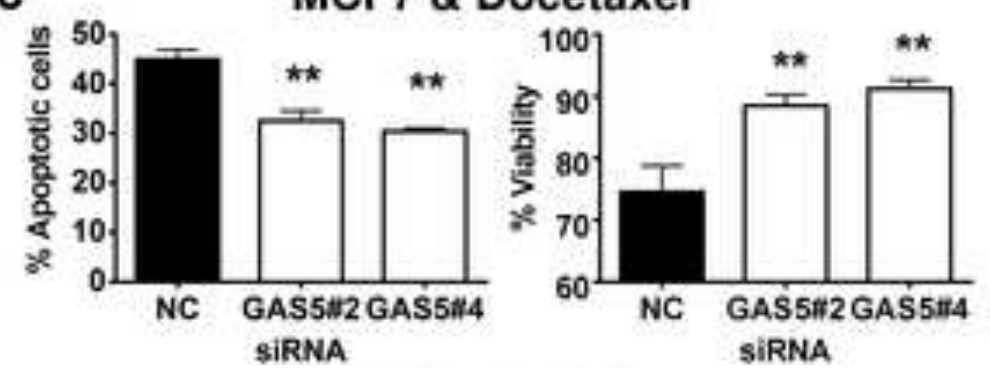

e
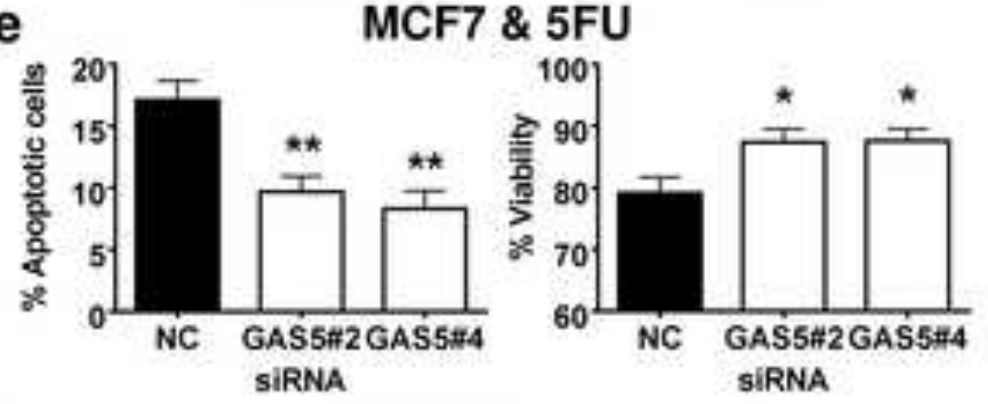

g
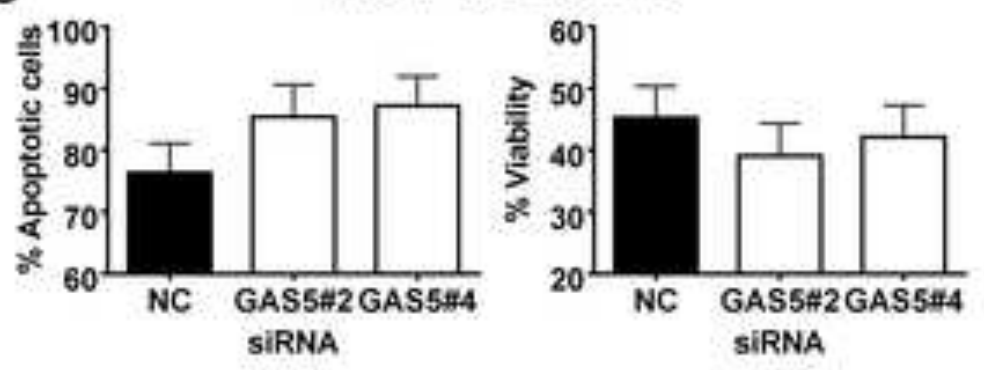

b
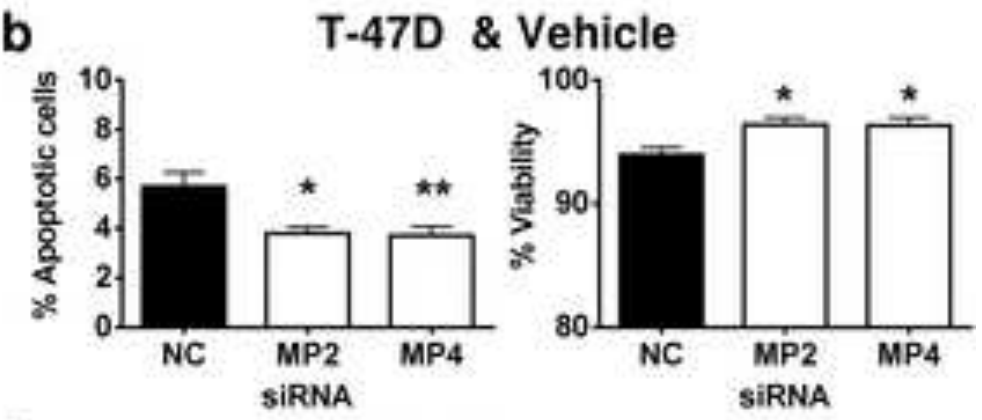

d
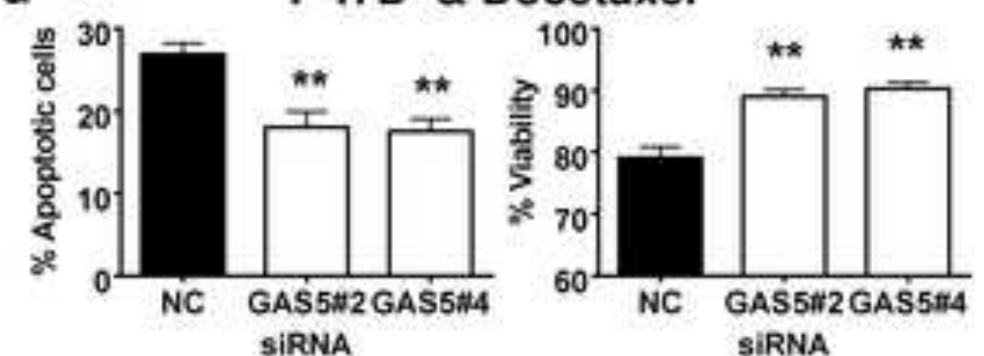

f
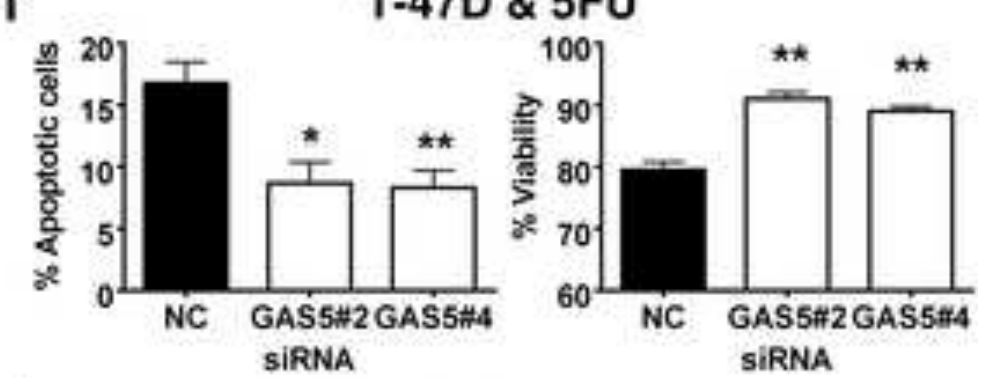

h
T-47D \& Imatinib
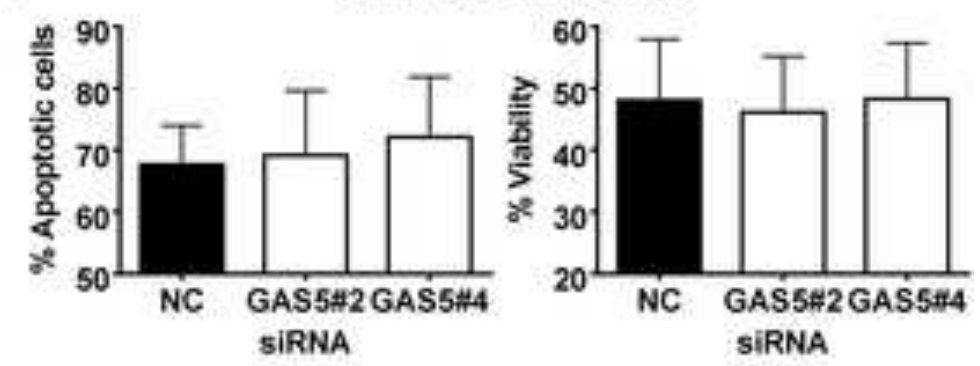
a

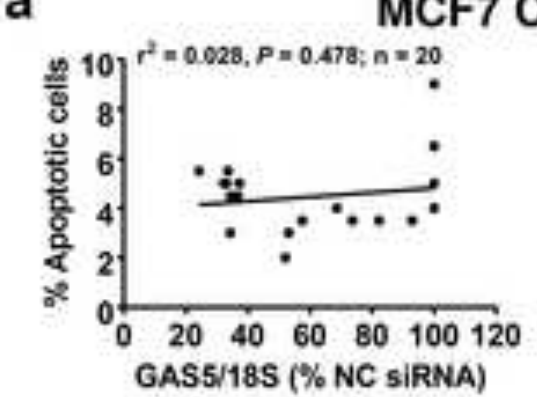

MCF7 Control

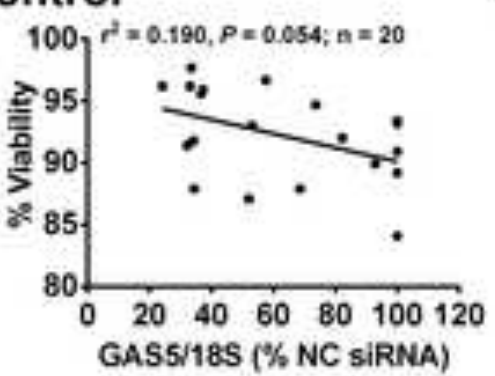

MCF7 \& UV-C
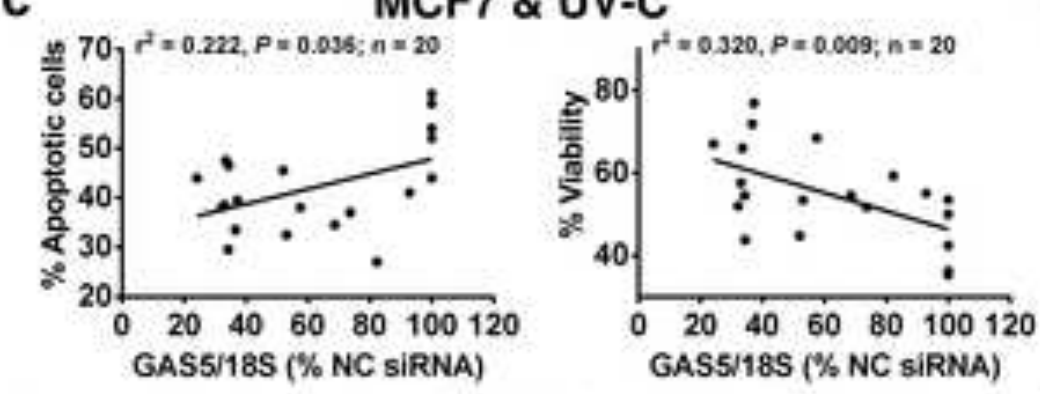

b

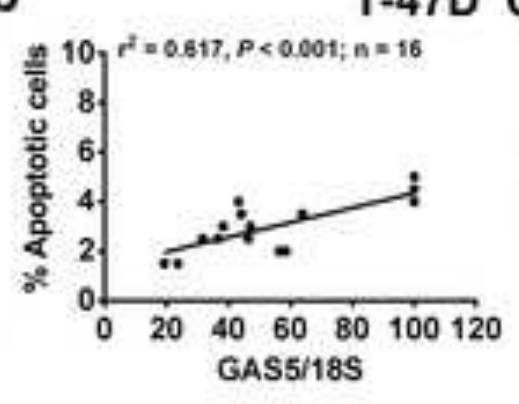

d

\section{MCF7 \& Docetaxel}
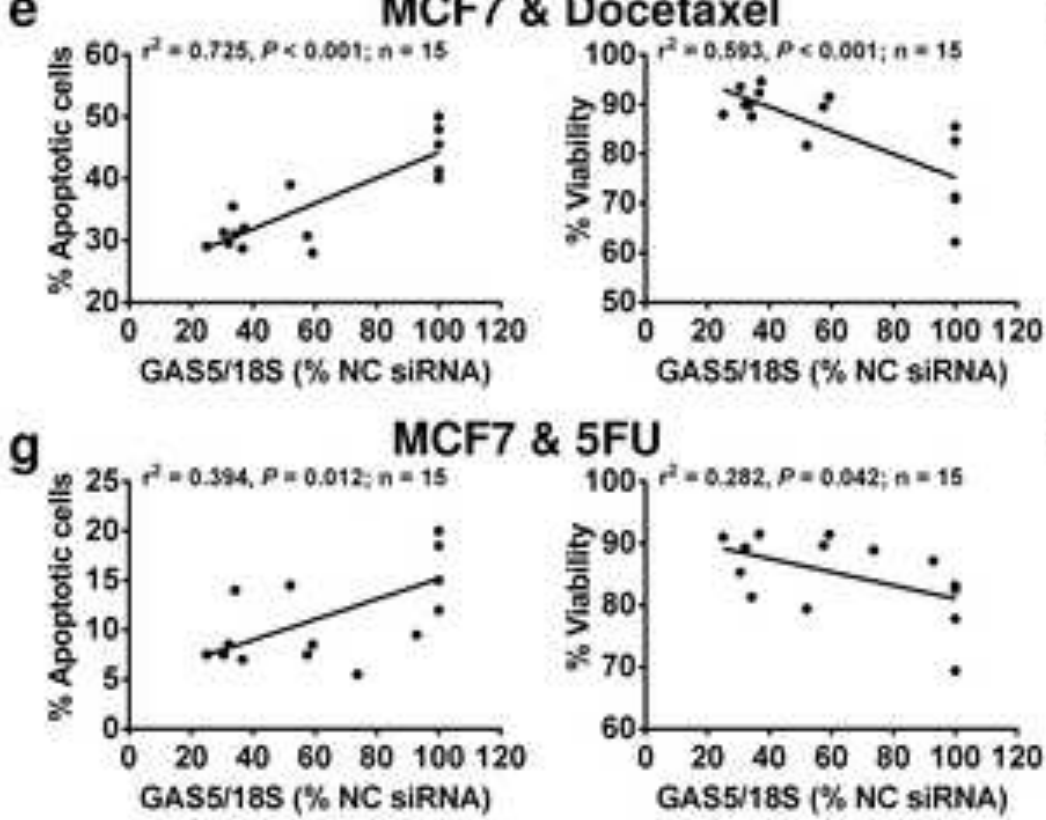

MCF7 \& 5FU

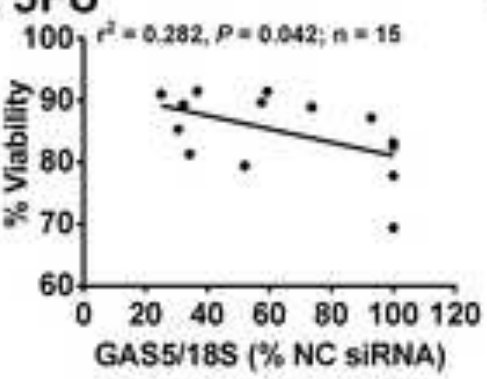

$$
\text { d }
$$

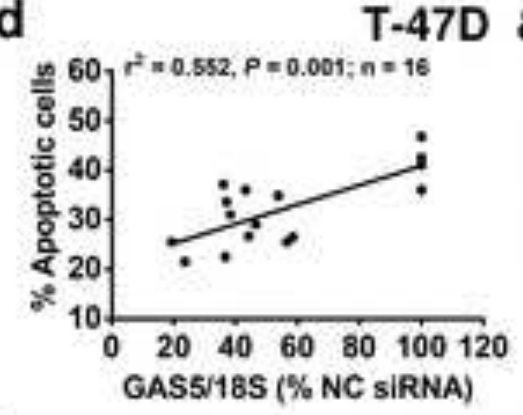

\section{T-47D \& Docetaxel}
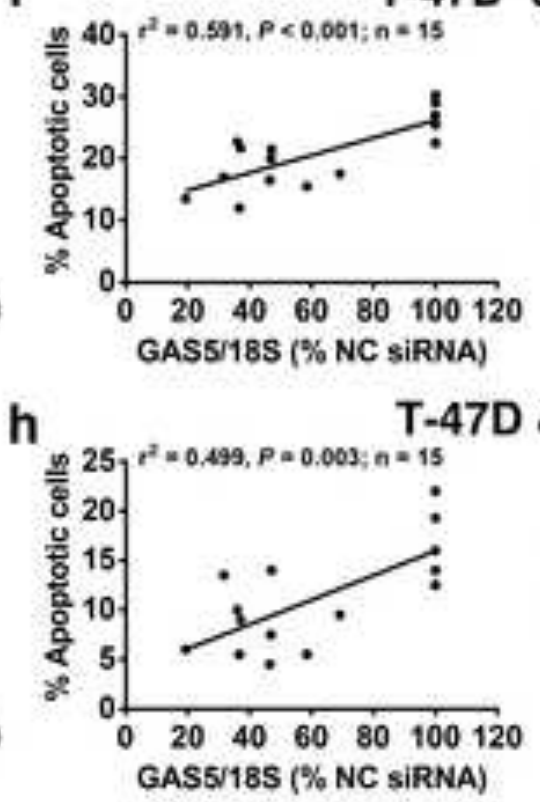
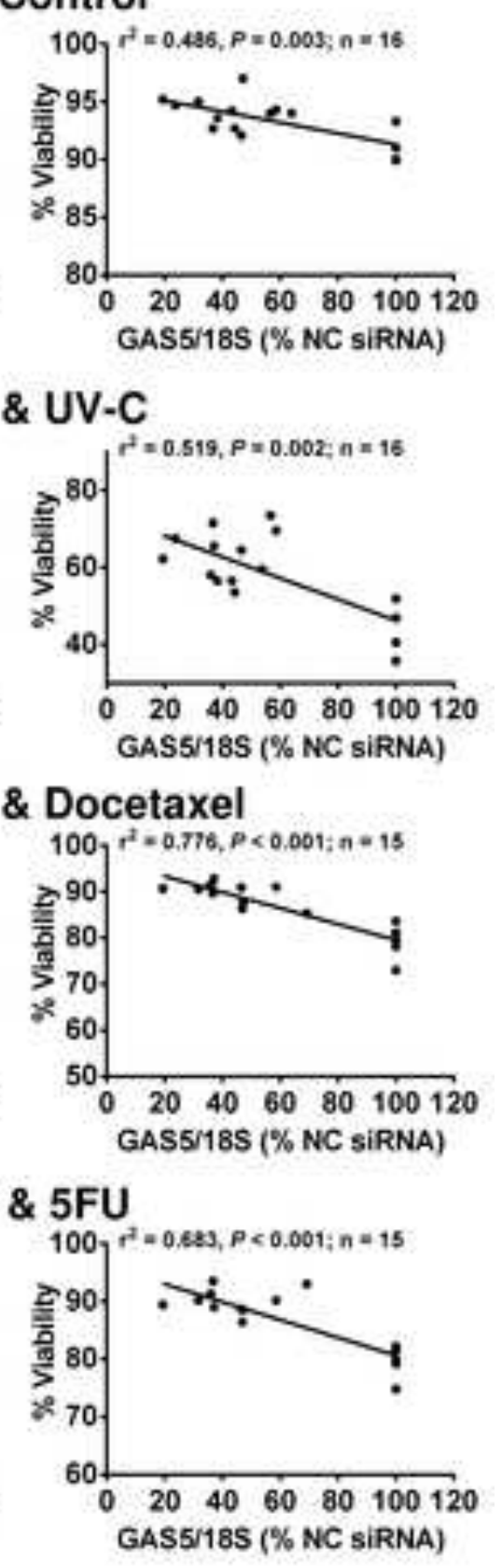
Figure 5
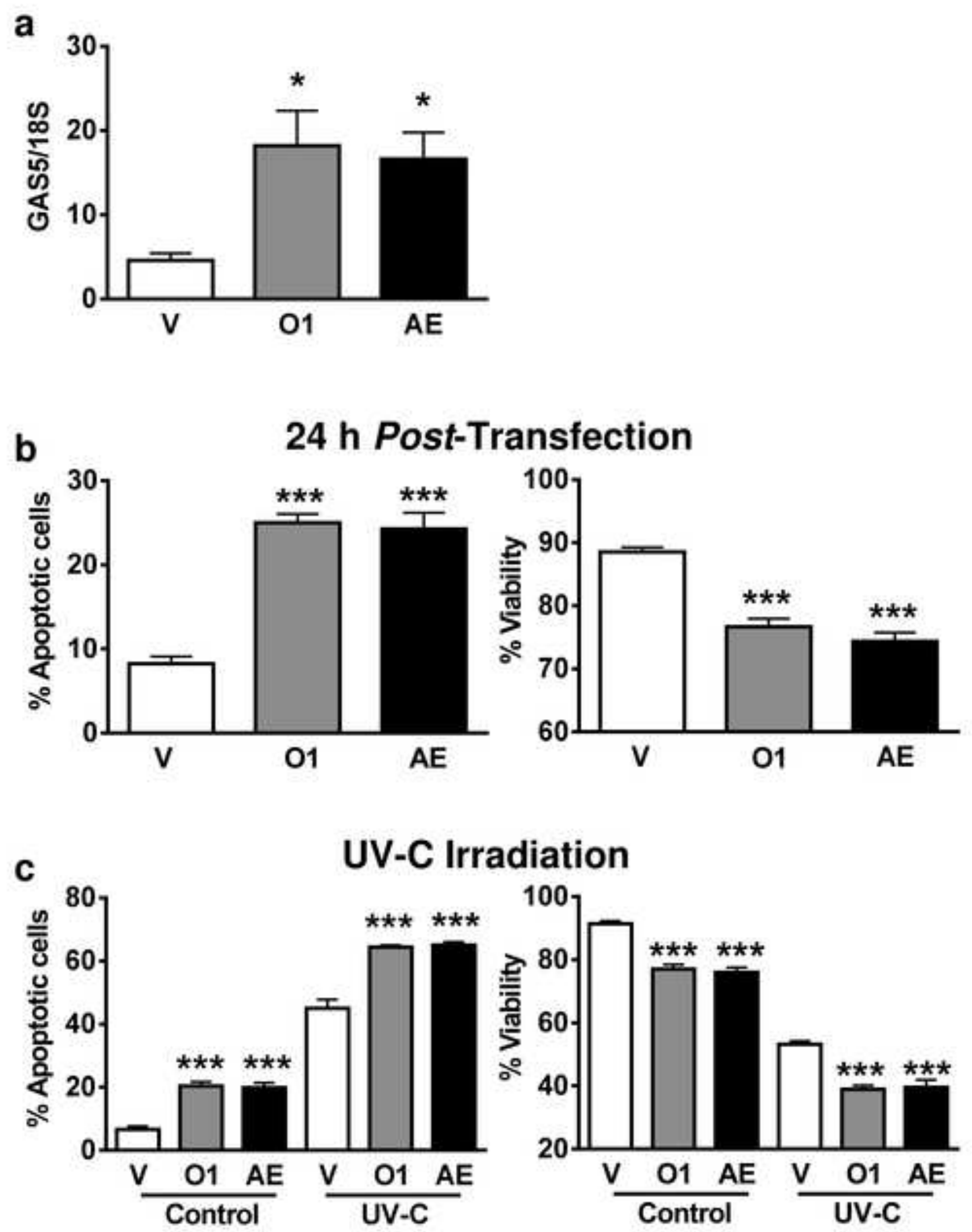
Figure 6
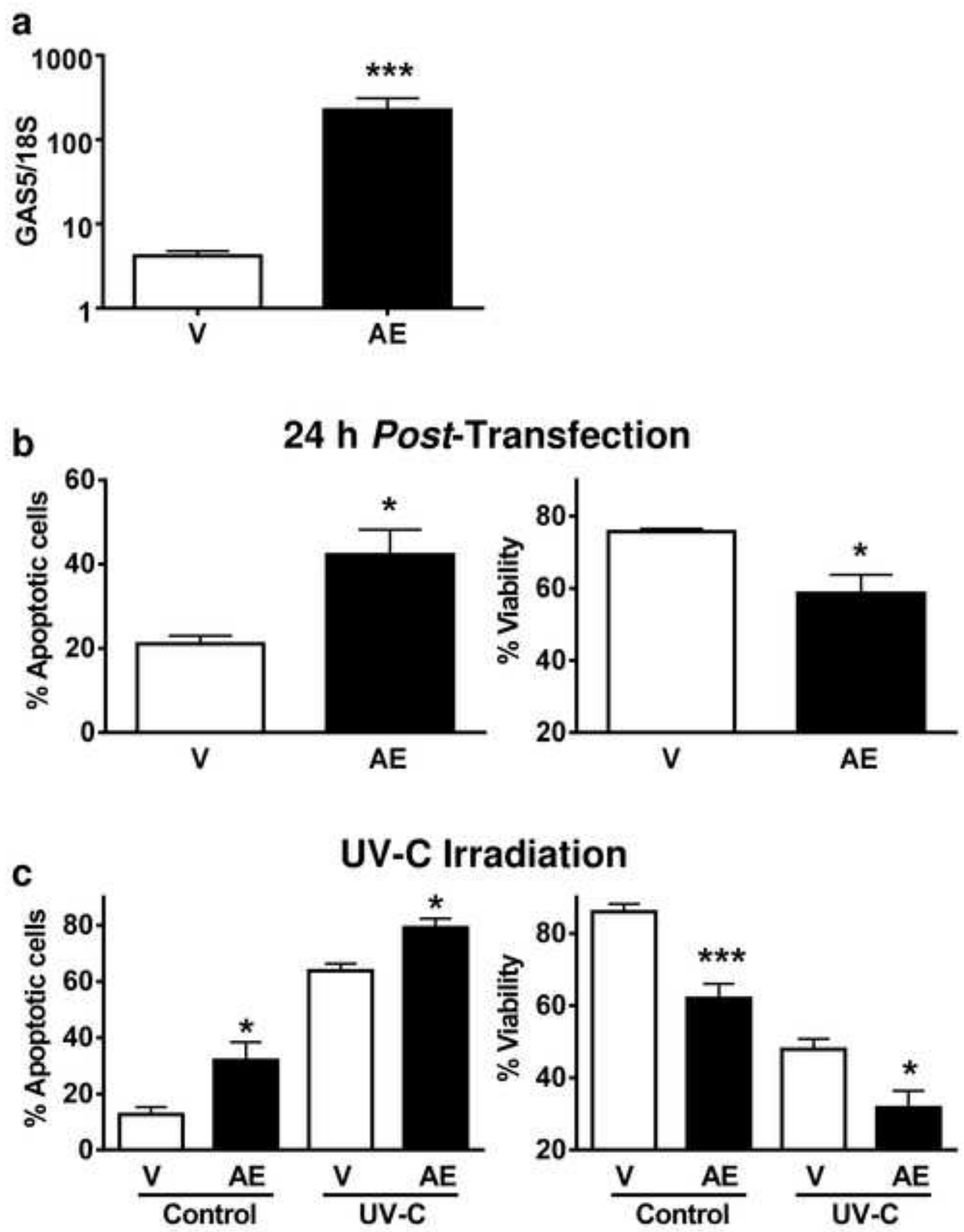
Figure 7
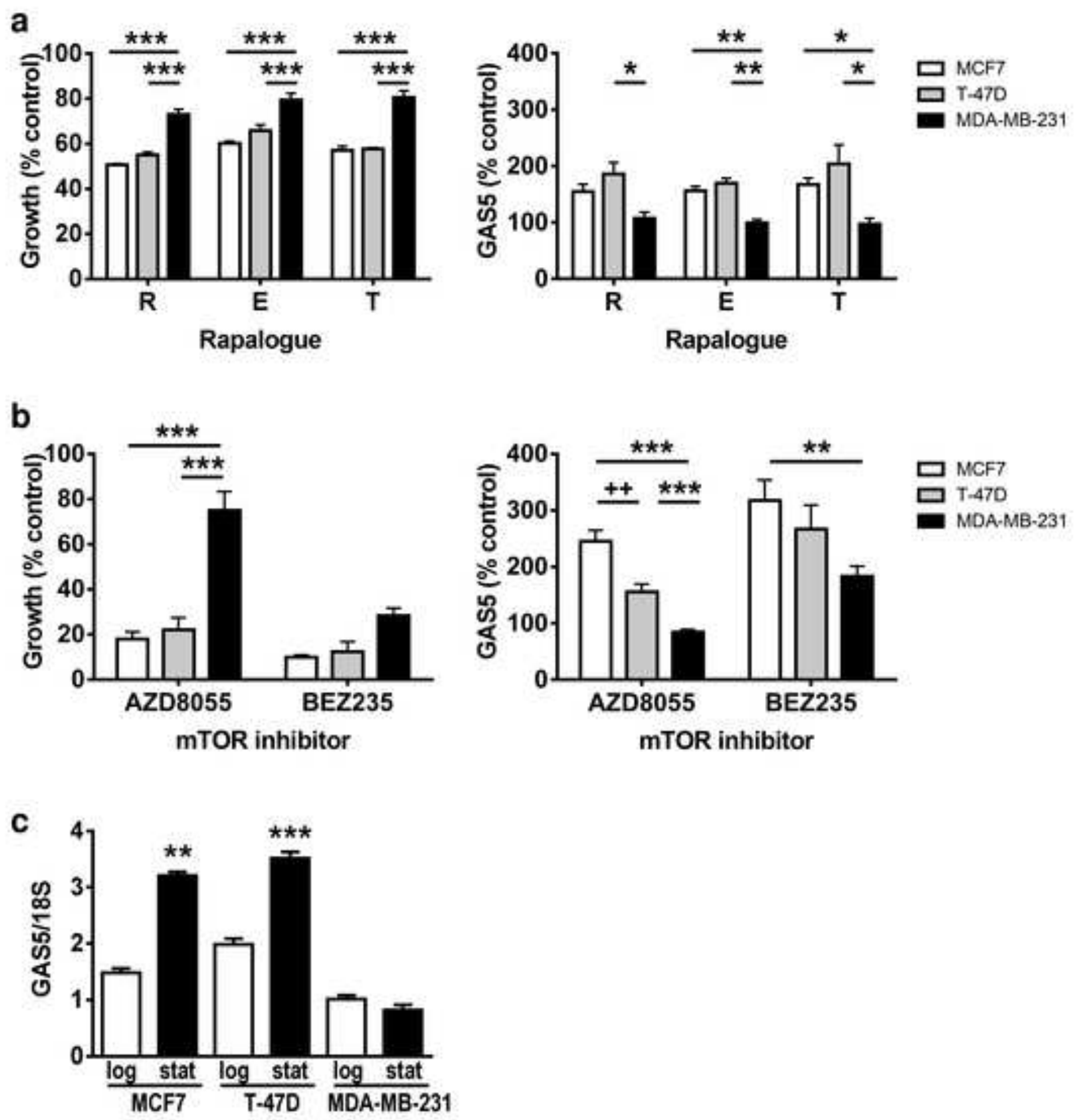